\title{
Advances in the biological effects of terahertz wave radiation
}

\author{
Li Zhao, Yan-Hui Hao and Rui-Yun Peng*
}

\begin{abstract}
The terahertz $(\mathrm{THz})$ band lies between microwave and infrared rays in wavelength and consists of non-ionizing radiation. Both domestic and foreign research institutions, including the army, have attached considerable importance to the research and development of $\mathrm{THz}$ technology because this radiation exhibits both photon-like and electron-like properties, which grant it considerable application value and potential. With the rapid development of $\mathrm{THz}$ technology and related applications, studies of the biological effects of $\mathrm{THz}$ radiation have become a major focus in the field of life sciences. Research in this field has only just begun, both at home and abroad. In this paper, research progress with respect to $\mathrm{THz}$ radiation, including its biological effects, mechanisms and methods of protection, will be reviewed.
\end{abstract}

Keywords: Terahertz, Radiation, Biological effects, Progress

\section{Introduction}

Essentially, $\mathrm{THz}$ is an electromagnetic wave with frequencies ranging from $0.3 \mathrm{THz}$ to $3 \mathrm{THz}$ and wavelengths ranging from $0.1 \mathrm{~mm}$ to $1 \mathrm{~mm}$. THz waves were formally named in the late 1980s, before which time they were collectively referred to as far-infrared rays. Because of the limited availability of effective $\mathrm{THz}$-generating sources and $\mathrm{THz}$-sensitive detectors, there has been very little research into this band; therefore, this band is also called the THz Gap. The term THz Gap is applicable in the following two respects: First, the THz band is located between millimeter waves and infrared rays, both of which bands have been more extensively investigated, thus forming a relatively undeveloped "blank." Second, studies of the long-wavelength regime, of which the $\mathrm{THz}$ band is a part, rely predominantly on electronics, whereas studies of the short-wavelength regime rely predominantly on photonics, resulting in a "gap" between these two research fields.

Compared with other bands, the $\mathrm{THz}$ band offers the following unique advantages: First, $\mathrm{THz}$ pulse widths on the subpicosecond scale allow for the facile analysis of various materials (such as liquids, semiconductors, superconductors, biological samples, etc.) through the technology of time-resolved transient spectroscopy. Second, a

\footnotetext{
*Correspondence: ruiyunpeng18@126.com

Department of Experimental Pathology, Beijing Institute of Radiation Medicine, Beijing 100850, China
}

(c) 2014 Zhao et al.; licensee BioMed Central Ltd. This is an Open Access article distributed under the terms of the Creative Commons Attribution License (http://creativecommons.org/licenses/by/4.0), which permits unrestricted use, distribution, and reproduction in any medium, provided the original work is properly credited. The Creative Commons Public Domain Dedication waiver (http://creativecommons.org/publicdomain/zero/1.0/) applies to the data made available in this article, unless otherwise stated.
THz pulse source must produce only a few cycles of oscillation, and the frequency range of each single pulse spans from the range of $\mathrm{GHz}$ (giga- $\mathrm{Hz}$ ) to $10 \mathrm{THz}$. This feature of $\mathrm{THz}$ sources is beneficial for the analysis of the spectral properties of a wide range of sample materials. Third, $\mathrm{THz}$ radiation is highly coherent, including strong temporal coherence and strong spatial coherence. This property assists in the accurate acquisition of the refractive indices and absorption coefficients of samples. Fourth, THz photons possess very low energies; therefore, $\mathrm{THz}$ radiation does not cause tissue damage or harmful ionization and is thus highly suitable for biopsy. Fifth, $\mathrm{THz}$ radiation offers strong penetration power for non-polar substances and can be used for detection. Sixth, THz waves are strongly absorbed by polar molecules, meaning that $\mathrm{THz}$ radiation can be used to study material compositions by analyzing the corresponding spectroscopic characterizations of the materials and can be used in product quality control.

In recent years, research and technology in the field of $\mathrm{THz}$ science has undergone tremendous development. In addition to $\mathrm{THz}$ radiation sources, remarkable developments have also been made in traditional $\mathrm{THz}$ detection, $\mathrm{THz}$ spectroscopy, $\mathrm{THz}$ imaging studies, $\mathrm{THz}$ radar, $\mathrm{THz}$ remote sensing, $\mathrm{THz}$ communication, $\mathrm{THz}$ measurement, and $\mathrm{THz}$ applications for non-damaging methods of detection as well as $\mathrm{THz}$ technology for use in material characterization and environmental monitoring. Research has been conducted in the petrochemical, aerospace, and 
biomedical industries as well as by the military and agencies concerned with national defense and national security, among others. Naturally, this extensive research program has aroused worldwide concern. With the rapid development of $\mathrm{THz}$ science and technology, exploration of the biological effects of $\mathrm{THz}$ radiation has become a major new effort in the field of life sciences. At present, research in this field, both at home and abroad, is still in its initial stages.

In this paper, research progress with respect to $\mathrm{THz}$ radiation, including its biological effects, mechanisms and methods of protection, will be reviewed.

\section{Biological effects of $\mathrm{THz}$ radiation}

At present, studies of the biological effects of $\mathrm{THz}$ radiation are largely supported by "THz-BRIDGE," an international cooperative project with the objective of studying the mechanisms involved in the interaction of $\mathrm{THz}$ radiation with cells and biological molecules to estimate the potential genotoxicity of $\mathrm{THz}$ radiation [1]. Meanwhile, the project is also committed to identifying the potential target organs, cells or sites of $\mathrm{THz}$ radiation, mostly focusing on lymphocytes, epidermal cells and cell membranes [2].

Similar to other bands of the electromagnetic spectrum, the biological effects of $\mathrm{THz}$ waves can be divided into thermal effects and non-thermal effects. Because of the low energy of $\mathrm{THz}$ waves and the overlap of their vibration and rotational levels with biological macromolecules, the nonthermal biological effects of $\mathrm{THz}$ radiation may demonstrate unique features and application prospects [3].

To study the thermal effects of $\mathrm{THz}$ waves, Wilmink et al. [4] have exposed human cells to $\mathrm{THz}$ radiation $(2.52 \mathrm{THz}$, $227 \mathrm{~mW} / \mathrm{cm}^{2}$, durations of $1 \sim 40 \mathrm{~min}$ ). They found that the vast majority of cells underwent apoptosis or necrosis after being exposed for $20 \mathrm{~min}$ or longer; $60 \%$ of Jurkat cells survived for $30 \mathrm{~min}$, and only 20 percent lived to $40 \mathrm{~min}$. In a subsequent study, human dermal fibroblasts were exposed to continuous THz radiation $\left(2.52 \mathrm{THz}, 84.8 \mathrm{~mW} / \mathrm{cm}^{2}\right.$, durations of $5,10,20,40$, and 80 minutes). It was found that cell viability was significantly affected when cellular temperatures increased by $3{ }^{\circ} \mathrm{C}$, and the expression of both heat shock proteins and DNA damage markers tended to increase. Compared with the radiation groups, the groups subjected to hyperthermic exposure $\left(3^{\circ} \mathrm{C}\right.$ higher than physiological conditions) exhibited equivalent levels of heat shock protein expression [5]. These findings suggested that radiation at $2.52 \mathrm{THz}$ generates predominantly thermal effects in mammalian cells.

As a major aspect of the study of related mechanisms, the non-thermal biological effects of $\mathrm{THz}$ waves have received greater attention. Bourne et al. [6] have exposed primarily cultured human keratinocytes and ND 7/23 cell lines characterized by sensory neurons to $0.14 \mathrm{THz}$ radiation for $80 \mathrm{~ns}$, with power densities ranging from $24 \mathrm{~mW} /$ $\mathrm{cm}^{2}$ to $62 \mathrm{~mW} / \mathrm{cm}^{2}$, but no changes occurred in the glutathione and heat shock protein 70 levels, which are typically indicators of the degree of stress response. Through the observation of the effects of $\mathrm{THz}$ radiation on neurons in vitro, Ol'shevskaia et al. [7] have observed that $\mathrm{THz}$ radiation causes injury to the morphology of neurons in a power- and wavelength-dependent manner.

Meanwhile, there have been many negative results in the study of the biological effects of $\mathrm{THz}$ radiation. Studies have indicated no effects of $\mathrm{THz}$ radiation on the differentiation or cell viability of human keratinocytes or neurons at a frequency of $0.14 \mathrm{THz}$ or a power of $0.45 \mathrm{~J} / \mathrm{cm}^{2}[6,8]$. In addition, $\mathrm{THz}$ radiation has also been found to have no significant effect on the morphology, adhesion, proliferation and differentiation of human epithelial and embryonic stem cells as well as the chromosomes of human lymphocytes $[9,10]$.

\section{Biological mechanisms involved in THz radiation}

$\mathrm{THz}$ radiation may interact with cellular components at multiple levels, including chromosomes, DNA (deoxyribonucleic acid), genes and proteins.

At the level of DNA and chromosomes, Hintzsche et al. [11] have exposed a monolayer-cultured humanhamster hybrid cell line to a $0.106 \mathrm{THz}$ radiation source for $0.5 \mathrm{~h}$, with power densities ranging from $0.043 \mathrm{~mW} /$ $\mathrm{cm}^{2}$ to $4.3 \mathrm{~mW} / \mathrm{cm}^{2}$. The results indicated that the $\mathrm{THz}$ radiation affected chromatid separation during the mitotic anaphase and telophase. Recently, several studies have indicated that the non-thermal effects of $\mathrm{THz}$ radiation may affect the stability of DNA by establishing a system in vitro, leading to chromosomal aberrations of human lymphocytes and genetic changes during the differentiation of mouse stem cells [12-16].

At the levels of genes and protein, the USA Air Force Research Laboratory [5] has studied the genetic changes in Jurkat cells exposed to continuous $\mathrm{THz}$ radiation (2.52 $\mathrm{THz}, 227 \mathrm{~mW} / \mathrm{cm}^{2}$, durations of $\left.1 \sim 40 \mathrm{~min}\right)$. They observed that the $\mathrm{THz}$ radiation primarily affected genes encoding inflammatory cytokines, including IL2-inducible T-cell kinase (ITK), integrin-linked kinase-associated serine/threonine phosphatase (ILRAP), RAD1, interleukin 6 (IL6), and interleukin 8 (IL8). Bock et al. [13] have investigated the relationship between broad-spectrum $\mathrm{THz}$ radiation and genetic changes and have found that the application of $\mathrm{THz}$ irradiation accelerated cell differentiation by activating the transcription factor peroxisome proliferator-activated receptor gamma (PPAR $\gamma$ ), indicating that $\mathrm{THz}$ radiation may be a potential tool for cellular reprogramming. Alexandrov et al. [14,15] have observed changes in gene expression in mesenchymal stem cells following exposure to $2.52 \mathrm{THz}$ radiation for $2 \mathrm{~h}$ under non-thermal conditions, including changes in adiponectin; solute carrier family 2 (facilitated glucose transporter), 
member 4 (GLUT4); and PPARy. Titova et al. $[17,18]$ have exposed human skin tissue to $0.2 \sim 2.5 \mathrm{THz}$ radiation for $10 \mathrm{~min}$. As a result, the expression of more than half of the epidermal differentiation complex (EDC), which is predominantly involved in epidermal differentiation and is often highly expressed in skin cancer and other diseases, changed at the gene level. At the same time, they also observed that $\mathrm{THz}$ radiation could induce significant alterations in the phosphorylation of $\mathrm{H} 2 \mathrm{AX}$, indicating that $\mathrm{THz}$ radiation could lead to potential DNA damage in skin tissues. Kim et al. [19] have irradiated mouse skin with femtosecondterahertz (fs-THz) radiation and, through genomic analysis, found that transforming growth factor-beta (TGF- $\beta$ ) mediated the damage response of the skin. Recently, E. coli/ pKatG-gfp biosensor cells have been used to study the biological effects of $\mathrm{THz}$ radiation. The results demonstrated that exposure to $\mathrm{THz}$ radiation at wavelengths of 130, 150, and $200 \mu \mathrm{m}$ and a power of $1.4 \mathrm{~W} / \mathrm{cm}^{2}$ induced changes in green fluorescent protein (GFP) fluorescence values and thus modified the expression of GFP [20].

However, there have also been some negative results in the study of the biological mechanisms involved in $\mathrm{THz}$ radiation. Hintzsche et al. [21] have exposed $\mathrm{HaCaT}$ and HDF cells to $\mathrm{THz}$ radiation for $2 \mathrm{~h}, 8 \mathrm{~h}$, and $24 \mathrm{~h}$ at various power intensities ranging from 0.04 to $2 \mathrm{~mW} / \mathrm{cm}^{2}$, and no DNA strand breakage or chromosomal damage was observed. In their follow-up study, at higher frequencies $(0.380$ and $2.520 \mathrm{THz})$, non-ionizing radiation did not induce genomic damage in human skin cells [22].

\section{Research on materials for protection against THz radiation}

The development and application of protective/shielding materials constitute an effective means of ensuring the survival of personnel and weapon systems for future battlefield applications of technologies; such studies are therefore highly valued in the world's major military nations. Many patents have been filed abroad in regard to protection/shielding materials that are compatible with multiple bands, and several domestic units have also developed multi-band camouflage screens that are compatible with visible light, infrared, and radar and are designed for stealth to achieve multi-band protection/shielding. Although considerable achievements have been made with respect to protection/shielding materials that are effective against multiple bands, including the microwave and infrared bands, a great deal of development is still required in the $\mathrm{THz}$ band.

Liu et al. [23] have studied the $\mathrm{THz}$ spectra of four stealth cloths, including gray shielding cloth, brick red shielding cloth, and light and dark calibration shielding cloth. The results indicated that the shielding effectiveness of these four cloths was no less than $30 \mathrm{~dB}$, suggesting that these cloths could be effective in shielding electronic devices against microwave or $\mathrm{THz}$ waves to prevent information leakage or interference. The gray and brick red shielding cloths exhibited better performance, with shielding effectiveness exceeding $60 \mathrm{~dB}$ and as high as $72.5 \mathrm{~dB}$ in the band from 0.33 to $1.15 \mathrm{THz}$. These four shielding cloths demonstrated a good shielding effect against $\mathrm{THz}$ radiation, especially the gray shielding cloth. These cloths would considerably hinder $\mathrm{THz}$ detection if they were to be applied to aerospace or military equipment.

Thus far, however, most studies have focused on the shielding effects of materials for electronic equipment; there has been very little investigation into the protection of humans against $\mathrm{THz}$ radiation. Therefore, one of the key problems currently facing the field of $\mathrm{THz}$ research is the study of materials for the protection of humans from $\mathrm{THz}$-wave radiation.

\section{Conclusions}

As a typical frontier cross-disciplinary science, THz science integrates the characteristics of both electronics and photonics and represents various unique mechanisms and methods that require elucidation, with the potential to lay the foundation for the next generation of science and technology and promote the development of information technology after the Moore era. $\mathrm{THz}$ science may lead to revolutionary developments and breakthroughs in science and technology, including military applications. However, studies of the biological effects of $\mathrm{THz}$ radiation are still lacking, far behind the development of the corresponding applied research. Therefore, cross-integration involving physics, biology, medicine, materials science and other fields should be strengthened in the field of $\mathrm{THz}$ science to advance the research and biomedical applications of $\mathrm{THz}$ waves. The scientific problems that have yet to be resolved include the interaction between $\mathrm{THz}$ waves and biological macromolecules, the mechanisms of this interaction, the biological effects of $\mathrm{THz}$ radiation on specific tissues and cells, and the key technologies and equipment involved in the biomedical applications of $\mathrm{THz}$ radiation.

The emergence and development of each new major technology for biological spectroscopy has caused a revolution in the field of biology. As an important strategic resource, $\mathrm{THz}$ science will contribute immeasurably to the life sciences and clinical medicine. However, the determination of whether it can play a role as significant as that of $\mathrm{X}$-rays still requires a global effort.

\section{Abbreviations}

THz: Terahertz; GHz: Giga Hz; DNA: Deoxyribonucleic acid; ITK: IL2 inducible T cell kinase; ILRAP: Integrin-linked kinase-associated serine/threonine phosphatase; IL6: Interleukin 6; IL8: Interleukin 8; PPARY: Peroxisome proliferator-activated receptor gamma; GLUT4: Solute carrier family 2 (facilitated glucose transporter), member 4; EDC: Epidermal differentiation complex; fs-THz: Femtosecond-terahertz; TGF- $\beta$ : Transforming growth factor-beta; GFP: Green fluorescent protein. 


\section{Competing interests}

The authors declare that they have no competing interests.

\section{Authors' contributions}

LZ participated in the design of the study, performed the literature review YH drafted the manuscript. RP conceived the study and assisted in drafting the manuscript. All authors read and approved the final manuscript.

Received: 15 August 2014 Accepted: 14 November 2014

Published online: 02 December 2014

\section{References}

1. Quality of Life and Management of Living Resources Key Action 4 Environment and Health. [http://www.frascati.enea.it/THz-BRIDGE/reports/ THz-BRIDGE\%20Final\%20Report.pdf]

2. Jo SJ, Yoon SY, Lee JY, Kim KT, Jung S, Park J, Park GS, Park WY, Kwon O: Biological effects of femtosecond-terahertz pulses on C57BL/6 mouse skin. Ann Dermatol 2014, 26:129-132.

3. Feng $\mathrm{H}$, Li F, Chen TN: Current situation and future trends for $\mathrm{THz}$ biomedicine. J Thz Sci Electron Inf Technol 2013, 11:827-835.

4. Wilmink GJ, Rivest BD, Ibey BL, Roach WP: Determination of death thresholds and identification of terahertz $(\mathrm{THz})$ specific gene expression signatures. Lasers Surg Med 2010, 42(17):22.

5. Wilmink GJ, Rivest BD, Roth CC, Ibey BL, Payne JA, Cundin LX, Grundt JE, Peralta X, Mixon DG, Roach WP: In vitro investigation of the biological effects associated with human dermal fibroblasts exposed to $2.52 \mathrm{THz}$ radiation. Lasers Surg Med 2011, 43:152-163.

6. Bourne N, Clothier RH, D'Arienzo M, Harrison P: The effects of terahertz radiation on human keratinocyte primary cultures and neural cell cultures. Altern Lab Anim 2008, 36:667-684.

7. Ol'shevskaialu S, Kozlov AS, Petrov AK, Zapara TA, Ratushniak AS: Influence of terahertz (submillimeter) laser radiation on neurons in vitro. ZhVysshNervDeiatlm I P Pavlova 2009, 59:353-359.

8. Clothier $\mathrm{RH}$, Bourne N: Effects of $\mathrm{THz}$ exposure on human primary keratinocyte differentiation and viability. J Biol Phys 2003, 29:179-185.

9. Zeni O, Gallerano GP, Perrotta A, Romanò M, Sannino A, Sarti M, D'Arienzo M, Doria A, Giovenale E, Lai A, Messina G, Scarfi MR: Cytogenetic observations in human peripheral blood leukocytes following in vitro exposure to THz radiation: a pilot study. Health Phys 2007, 92:349-357.

10. Williams R, Schofield A, Holder G, Downes J, Edgar D, Harrison P, SiggelKing M, Surman M, Dunning D, Hill S, Holder D, Jackson F, Jones J, McKenzie J, Saveliev $Y$, Thomsen N, Williams $P$, Weightman $P$ : The influence of high intensity terahertz radiation on mammalian cell adhesion, proliferation and differentiation. Phys Med Biol 2013, 58:373-391.

11. Hintzsche $H$, Jastrow C, Kleine-Ostmann T, Stopper H, Schmid E, Schrader T: Terahertz radiation induces spindle disturbances in human-hamster hybrid cells. Radiat Res 2011, 175:569-574.

12. Alexandrov BS, Gelev V, Bishop AR, Usheva A, Rasmussen KO: DNA breathing dynamics in the presence of a terahertz field. Phys Lett A 2010, 374:1214.

13. Bock J, Fukuyo Y, Kang S, Phipps ML, Alexandrov LB, Rasmussen KØ, Bishop AR, Rosen ED, Martinez JS, Chen HT, Rodriguez G, Alexandrov BS, Usheva A: Mammalian stem cells reprogramming in response to terahertz radiation. PLOS One 2010, 5:e15806.

14. Alexandrov BS, Rasmussen KØ, Bishop AR, Usheva A, Alexandrov LB, Chong S, Dagon Y, Booshehri LG, Mielke CH, Phipps ML, Martinez JS, Chen HT, Rodriguez G: Non-thermal effects of terahertz radiation on gene expression in mouse stem cells. Biomed Opt Express 2011, 2:2679-2689.

15. Alexandrov BS, Phipps ML, Alexandrov LB, Booshehri LG, Erat A, Zabolotny J, Mielke $\mathrm{CH}$, Chen HT, Rodriguez G, Rasmussen KØ, Martinez JS, Bishop AR, Usheva A: Specificity and heterogeneity of terahertz radiation effect on gene expression in mouse mesenchymal stem cells. Sci Rep 2013, 3:1184.

16. Korenstein-Ilan A, Barbul A, Hasin P, Eliran A, Gover A, Korenstein R: Terahertz radiation increases genomic instability in human lymphocytes. Radiat Res 2008, 170:224-234.

17. Titova LV, Ayesheshim AK, Golubov A, Rodriguez-Juarez R, Woycicki R, Hegmann FA, Kovalchuk O: Intense THz pulses down-regulate genes associated with skin cancer and psoriasis: a new therapeutic avenue? Sci Rep 2013, 3:2363.

18. Titova LV, Ayesheshim AK, Golubov A, Fogen D, Rodriguez-Juarez R, Hegmann FA, Kovalchuk O: Intense $\mathrm{THz}$ pulses cause $\mathrm{H} 2 \mathrm{AX}$ phosphorylation and activate DNA damage response in human skin tissue. Biomed Opt Express 2013, 4:559-568.

19. Kim KT, Park J, Jo SJ, Jung S, Kwon OS, Gallerano GP, Park WY, Park GS: High-power femtosecond-terahertz pulse induces a wound response in mouse skin. Sci Rep 2013, 3:2296.

20. Demidova EV, Goryachkovskaya TN, Malup TK, Bannikova SV, Semenov Al, Vinokurov NA, Kolchanov NA, Popik VM, Peltek SE: Studying the nonthermal effects of terahertz radiation on E. coli/pKatG-GFP biosensor cells. Bioelectromagnetics 2013, 34:15-21.

21. Hintzsche H, Jastrow $C$, Kleine-Ostmann T, Kärst U, Schrader T, Stopper H: Terahertz electromagnetic fields $(0.106 \mathrm{THz})$ do not induce manifest genomic damage in vitro. PLOS One 2012, 7:e46397.

22. Hintzsche $H$, Jastrow $C$, Heinen B, Baaske K, Kleine-Ostmann T, Schwerdtfeger $M$, Shakfa MK, Kärst U, Koch M, Schrader T, Stopper H: Terahertz radiation at 0.380 $\mathrm{THz}$ and $2.520 \mathrm{THz}$ does not lead to DNA damage in skin cells in vitro. Radiat Res 2013, 179:38-45.

23. Liu YY, Wu FP, Chen YJ, Zhang CL, Geng YZ, Li FL: Experimental studies on terahertz spectrum of stealthy materials. LASER \& InFRARED 2009, 39:618-621.

doi:10.1186/s40779-014-0026-x

Cite this article as: Zhao et al:: Advances in the biological effects of terahertz wave radiation. Military Medical Research 2014 1:26.

\section{Submit your next manuscript to BioMed Central and take full advantage of:}

- Convenient online submission

- Thorough peer review

- No space constraints or color figure charges

- Immediate publication on acceptance

- Inclusion in PubMed, CAS, Scopus and Google Scholar

- Research which is freely available for redistribution

Submit your manuscript at www.biomedcentral.com/submit
C Biomed Central 